\title{
Plasma Cell Gingivitis in a Patient with Partially Edentulous Arches: A Rare Case Report
}

\author{
${ }^{1}$ Dr Smitha J D, ${ }^{2}$ DrPrathibha Rani R M, DrSrishaBasappa, ${ }^{4}$ Dr Archana Patil \\ ${ }^{1}$ Pg Student Of Oral Medicine And Radiology; Farooqia Dental College And Hospital Mysore; \\ ${ }^{2}$ Reader Of Oral Medicine And Radiology \\ ${ }^{3}$ HOD Of Oral Medicine And Radiology \\ ${ }^{4}$ Senior Lecturer Of Oral Medicine And Radiology
}

\begin{abstract}
Plasma cell gingivitis is a rare condition characterized by diffuse and massive infiltration of plasma cells into the sub-epithelial connective tissue.It is considered as a hypersensitive reaction to an allergen, the etiology of this bizarre condition is still not properly understood.Plasma cell gingivitis is a rare benign condition of the gingiva characterized by well demarcated erythematous and oedematous gingiva often extending to the mucogingival junction. Here we are presenting a case of plasma cell gingivitis in a partially edentulous arch.The condition was diagnosed based on clinical and histopathologic findings. Early diagnosis is essential as plasma cell gingivitis has similar pathologic changes seen clinically as in leukaemia, HIV infection, discoid lupus erythematosus, atrophic lichen planus, desquamative gingivitis, or cicatrical pemphigoid which must be differentiated through hematologic and serologic testing.
\end{abstract}

Keywords: Allergen, benign condition, biopsy, edentulous arches, plasma cell gingivitis

\section{Introduction}

Plasma cell gingivitis (PCG) is a rare benign condition of the gingiva. It is marked by a dense infiltrate of normal plasma cells separated into aggregates by strands of collagen. The importance of this lesion is that it may cause severe gingival inflammation, discomfort, and bleeding and may mimic more serious conditions [1].Plasma Cell Gingivitis is a hypersensitivity reaction to some antigen, often flavouring agents or spices. Over the years, case reports of plasma cell gingivitis have been appeared in the dental literature [2,3].The allergens identified were mostly cinnamon aldehyde and cinnamon, used as flavouring agents in chewing gums and dentifrices $[4,5,6]$.Clinically, the gingiva appears red, friable and bleeds easily. Histopathologically, a dense and massive infiltration of mature plasma cells in the lamina propria is noted. Gingival ulceration is rare [7].Plasma cell gingivitis is reported with variety of other names such as atypical gingivostomatitis, plasmacytosis, idiopathic gingivostomatitis and allergic gingivostomatitis [3, 8].

Plasma cell gingivitis has been sub-dividedinto three types: a) caused by an allergen, b)neoplastic,

c)unknowncause [9]. This case report presents with plasma cell gingivitis in an edentulous arch and can be categorised as type 3 where identification of etiologic factor is elusive.Plasma Cell Gingivitis mimics lesions associated with discoid lupus erythematosus, lichen planus, cicatricial pemphigoid, leukaemia and myeloma, thus an early diagnosis in such cases is vital in patient's interest $[9,10]$.

\section{Case report}

A 57 year old female patient presented to the Department of Oral Medicine and Radiology, Farooqia Dental College and hospital, Mysore, Karnataka with the chief complaint of a reddish swollen gums in upper right front teeth region since one month"Fig.1".Clinically, patient presented with inflammation of the gingival tissues extending up tothemucogingival junction in the right maxillary canine and premolar region and gingival bleeding occurred with the slightest provocation. There was a negative Nikolskys sign with no cutaneous lesion. Patient had neither any significant medical history nor reported a history of mouth breathing or the use of chewing gum. Patient had undergone extraction of her teeth in the maxillary arch one month back due to mobility which was followed by erythematous swollen areas on gingiva.Provisionally it was diagnosed as atypical gingivitis.Haematological investigations were done to rule out leukaemia or other blood dyscrasias.Incisional biopsy was advised in right maxillary canine and premolarregion and processed for histopathological examination. 


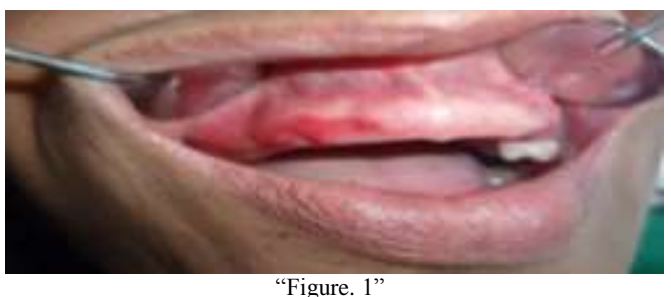

III. Histopathological examination

Microscopic examination revealedsurface epithelium which was parakeratinised stratified squamous of varying thickness with regions of thinned out epithelium and sharp rete ridges. Connective tissue was composed of dense diffuse chronic inflammatory cell infiltrate predominantly of plasma cells and lymphocytes, collagen fibers, endothelium lined blood vessels "Fig.2". Above features were indicative of plasma cell gingivitis or atypical gingivitis.

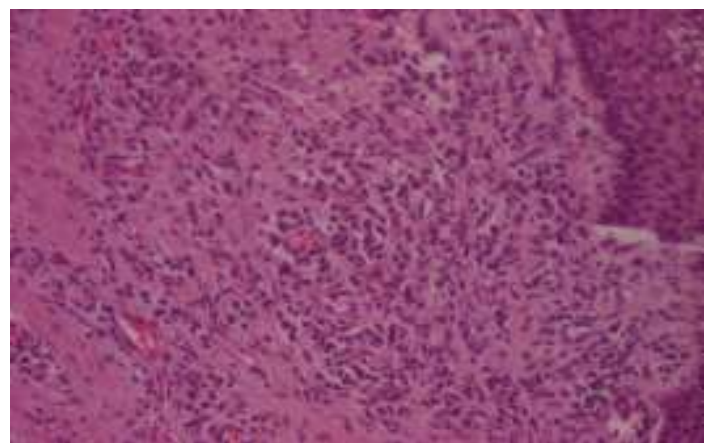

"Figure. 2"

Treatment plan was formulated. Patient was explained about the nature of the lesion. Oral hygiene instructions were given.Multivitamin tablets were given once daily for about 15 days, Triamcinolone acetonide $0.1 \%$ oral paste was given which was to be applied on the affected area half an hour after meals $5-6$ times daily. Patient was recalled after one week, after one week there was about 30 to 40 percent reduction in the erythematous component of the lesion"Fig.3".Prognosis was good .Followup was done after three weeks, there was about 50 percent reduction in the erythematous component of the lesion "Fig.4"and after six weeks about 80 percent of the lesion had subsided "Fig.5".

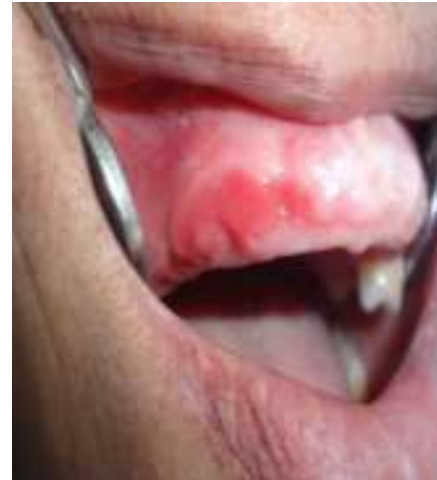

"Figure.3"

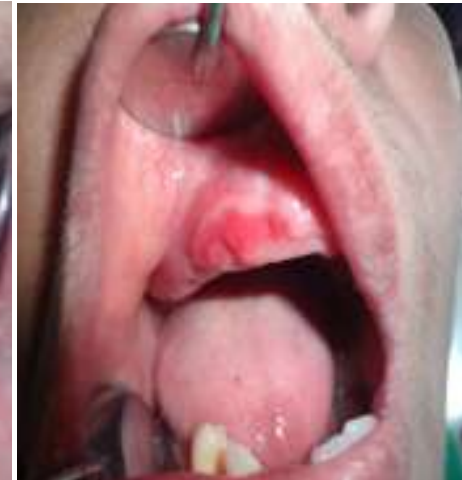

"Figure.4"

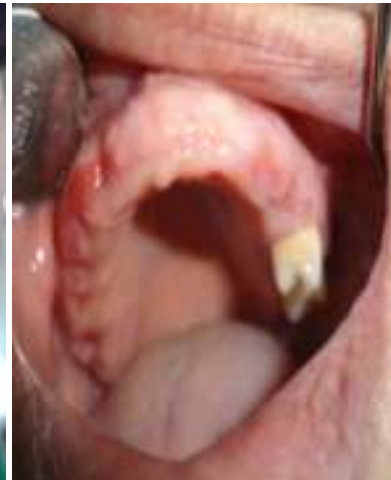

"Figure.5"

\section{Discussion}

Plasma cell gingivitis is a rare condition characterized by diffuse and massive infiltration of plasma cells into thesub epithelial gingival tissue[4].Clinically, the condition presents as a diffuse reddening together with oedematous swelling of the gingiva, with sharp demarcation along the muco-gingival border. The etiology of plasma cell gingivitis is not clear, but due to the presence of plasma cells many authors are of the opinion that it is an immunological reaction to allergens [10].Many authors suggest that it is an immunological reaction to allergens; these may occur in toothpaste, chewing gum, mint pastes and certain food[11, 12].

In the present case patient had noticed erythematous areas on gingiva which was extending up to mucogingival junction after extraction of her teeth due to mobility. Haematological examination excluded blood dyscrasias.Diagnosis was made based on histopathological examination of the biopsy specimen. 
Thehistopathological picture revealed replacement of underlying connective tissue by a population of cells predominantly made up of plasma cells thus indicating the diagnosis.

Management of plasma cell gingivitis includes various medical and surgical modalities with a wide range of success.It includestopical/systemic antihistaminic, corticosteroids, antimicrobials and surgical modalities, including, excision by laser, electrocoagulation. Present case responded successfully to multivitamin supplements and Triamcinolone acetonide $0.1 \%$ oral paste.

\section{Conclusion}

The case presented here highlights the presence of lesion in edentulous arch and history could not be related to any allergens.Thus, emphasizing the need for comprehensive history taking, examination and appropriate diagnostic tests in order to arrive at a definitive diagnosis and treatment plan for gingival conditions. Histopathological examination is the key for diagnosis of plasma cell gingivitis and to differentiate it from other similar lesions.

\section{References}

[1]. Serio FG, Siegel MA, Slade BE. Plasma cell gingivitis of unusual origin. A case report. J Periodontol 1991;62:390-3.

[2]. Newcomb GM, Seymour GJ, AdkinsKF: An unusual form of chronic gingivitis: an ultrastructural,histochemical and immunologic investigation. Oral Surg 1982; 53:488.

[3]. Bhaskar SN, Levin MP, Frisch J. Plasma cell granuloma of periodontal tissues. Report of 45 cases.Periodontics 1968; 6:272-6.

[4]. Macleod RI, Ellis JE. Plasma cell gingivitis related to the use of herbal toothpaste. Br Dent J. 1989; $166: 3756$.

[5]. Kerr DA, McClatchey KD, Regezi JA. Allergic gingivostomatitis (due to gum chewing) J Periodontol.1971; 42:709-12.

[6]. Anil S. Plasma cell gingivitis among herbal toothpasteusers. A report of three cases.J Contemp Dent Pract.2007; 8:4-13.

[7]. Gargiulo AV, Ladone JA, Ladone PA, Toto PD. Case report: Plasma cell gingivitis A. CDS Rev. 1995; 88:223.

[8]. Chandershekhar Joshi, Pradeep Shukla. Case report: Plasma cell gingivitis.Journal of Indian society of Periodontology, Mar-Apr 2015; 19(2).

[9]. Kerr DA, Mc Clatchey KD, Regezi JA. Idiopathic gingivostomatitisCheilitis glossitis, gingivitissyndrome: atypical gingivostomatis, plasma cell gingivitis, plasmacytosis of gingival. Oral Surg Oral MedOralPathol 1971; 32(3): 402-423.

[10]. Allen CM, Blozis, GG. Oral mucosal reactions to cinnamon-flavoured chewing gum. J Am Dent Assoc1988; 116:664-667.

[11]. Owings JR. An atypical gingivostomatitis: A report of four cases. J Periodontol 1969; 40:538-542.

[12]. Poswillo D. Plasmacytosis of the gingiva. Br J Oral Surg1968; 5:194-202. 